\title{
Apoptotic cell death and the proliferative capacity of human breast cancers
}

\author{
Gabriele A. Losa* and Riccardo Graber \\ Laboratorio di Patologia Cellulare, Istituto cantonale di Patologia, CH-6601 Locarno, Switzerland
}

Received 12 May 1997

Revised 7 August 1997

Accepted 2 January 1998

\begin{abstract}
The proliferative capacity (\%S-phase fraction), DNA ploidy, apoptosis frequency (DNA fragmentation) and steroid hormone receptor status (estrogen receptor, ER; progesterone receptor, PR) of 110 samples of human breast tissues with ductal invasive carcinoma were measured using biochemical and cytofluorimetric procedures. The DNA fragmentation had a left-skewed frequency distribution and an overall median value of $1.64 \%$, whilst the median $\%$ S-phase fraction was $8 \%$. The median \%DNA fragmentation and \%S-phase fraction were $1.96 \%$ and $16 \%$ in hyperdiploid tumours $(n=29$; DNA index $>1.1)$ higher than in hypodiploid tumors $(n=10$; DNA index $<0.96), 0.38 \%$ and $7.5 \%$. DNA diploid tumours $(n=71)$ had median \%DNA fragmentation and $\%$ S-phase values of $1.68 \%$ and $6 \%$, consistently lower than the median values of DNA hyperdiploid tumours. The ER content of hypodiploid tumours was about one half (median: $5.9 \mathrm{fmol} / \mathrm{mg}$ ) the median values in hyperdiploid $(10.6 \mathrm{fmol} / \mathrm{mg})$ and diploid tumours $(14.6 \mathrm{fmol} / \mathrm{mg})$. This may correlate with the lowest frequency of apoptosis in hypodiploid tumours, at least when measured by biochemical methods which only detect cells in the late phases of apoptosis. In contrast, the median PR was lowest in hyperdiploid tumours than in hypo and/or diploid tumours. The \%S-phase/\% fragmented DNA ratio for the hypodiploid tumours was 19.7, significantly higher than the ratios for hyperdiploid (8.2) and diploid tumours (3.6). These findings indicated that there is an imbalance between proliferative capacity and cell death or growth arrest in human breast tumours. This imbalance may well be linked to a loss of steroid hormone control.
\end{abstract}

Keywords: Apoptosis, human breast cancer, DNA ploidy, DNA fragmentation, steroid hormone receptors, \%S-phaseproliferative capacity

\section{Introduction}

Apoptosis is a physiological form of cell death that occurs in all tissues and in which cells committed to die undergo a series of characteristic morphological and biochemical changes $[8,25,32,40]$. Most of the events of the active or late phases of apoptosis are readily identified in cell cultures [14, 27,48]. However, cells of the estrogen-dependent breast cancer cell line MCF-7 do not undergo internucleosomal DNA fragmentation [35,44], which is usually considered to be a specific feature of apoptosis [33]. It is more difficult to recognize and quantify apoptosis in solid tissues under physiological or pathological conditions for several reasons. First, apoptosis itself is relatively rapid

\footnotetext{
${ }^{*}$ Corresponding author: Gabriele A. Losa, Ph.D., Laboratorio di Patologia Cellulare, Istituto cantonale di Patologia, CH-6601 Locarno, Switzerland. Tel.: +41 91 7562680; Fax: +41 91 7562691; E-mail: glosa@ guest.cscs.ch.
} 
in tissues, compared to the latent period [6,28]. Second, apoptotic cells are efficiently removed from a tissue by phagocytic elements and/or other committed cell systems [10]. Third, most of the methods currently available do not adequately identify the early phases of apoptosis, some of which probably involve specific biochemical and morphological changes in the plasma membrane, while the cells continue to appear overtly normal and healthy. It has been shown recently that the loss of lipid asymmetry by the exposure of phosphatidylserine on the outer membrane leaflet is one of the surface membrane events of apoptosis in some cell tissues [15]. This triggers signalling and transport membrane-bound enzymes in lymphoid cells [19] and activates the sphingomyelin cycle [20] with release of ceramide [21]. The better known changes, such as DNA fragmentation, chromatin condensation, membrane permeability changes and impaired mitochondrial activity $[37,45]$ occur later. Cancer tissues undergo additional changes, such as accelerated removal of apoptotic cells, mutation of tumour suppressor genes, abnormal expression of the death inhibiting gene bcl-2 [5,38], loss of Fas expression and function [24], and inactivation of ICE and other cytoplasmic proteases [9]. All these may greatly reduce apoptosis in neoplastic tissues. They may also explain why there appears to be so few apoptotic cells in many tumour tissues $[43,46]$. It has also been reported that the measurable rate of apoptosis is lower in human cancer tissues than in resting or physiologically active tissues, e.g., in pregnancy, or in vitro tumour cell systems $[5,6,16,17,19,27,30]$. Other biologic properties, such as the proliferation rate and the growth fraction [12,23], the invasive potential [13], the receptor status together with endocrine and paracrine signals [29] and altered interactions with the surrounding extracellular matrix [31,34] may influence the capacity of tumours to escape from control mechanisms and avoid apoptotic death. But there have been few reports on the frequency of the apoptotic process in human breast cancer. We have therefore attempted to quantify cell death and the proliferative capacity, DNA ploidy and receptor status to provide a clearer biological profile of invasive mammary carcinoma, when a patient first presents with this disease.

\section{Material and methods}

A total of 110 samples of invasive carcinoma were obtained from breast biopsies or from mastectomy of untreated patients (age range: 30-65 years) performed at the Institute of Pathology. The histologic diagnosis was invasive ductal carcinoma in most of the cases analyzed (92\%) and lobular carcinoma for the remaining $8 \%$.

\subsection{Tissue fractionation}

Each tumour tissue sample was cut into small pieces, frozen in liquid nitrogen and ground to a powder in liquid nitrogen. The pulverized tissue sample was divided into two aliquots, a large one for measuring estrogen receptors (ER), progesterone receptors (PR) and DNA fragmentation, and a small fraction $(80-100 \mathrm{mg}$ ) for determining the $\% \mathrm{~S}$-phase and DNA ploidy. The pulverized tissue samples were suspended in Tris/K/Mg buffer and homogenized with a teflon Potter homogenizer (3 times up and down at $1000 \mathrm{rpm}$ at $4^{\circ} \mathrm{C}$ ). The homogenate was centrifuged at $100,000 \times \mathrm{g}$ for $30 \mathrm{~min}$ at $4^{\circ} \mathrm{C}$ in a Beckman L5 ultracentrifuge. The supernatant was carefully recovered and assayed for ER and PR receptors by the Ligand Binding Assay (LBA), the "gold standard" biochemical method validated by the EORTC Receptor Group [4]. The microsomal pellet was incubated for $1 \mathrm{~h}$ at $50^{\circ} \mathrm{C}$ in $10 \mathrm{mM}$ Tris,

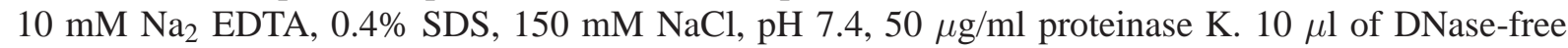
RNase A $(50 \mu \mathrm{g} / \mathrm{ml})$ were then added and incubation continued for $1 \mathrm{~h}$ at $37^{\circ} \mathrm{C}$, plus $5 \mathrm{~min}$ at $70^{\circ} \mathrm{C}$. 
An aliquot $(20 \mu \mathrm{l})$ of the microsomal lysate was examined by agarose gel electrophoresis for DNA fragments and the main sample was ultracentrifuged at $15,000 \times \mathrm{g}$ for $30 \mathrm{~min}$ at $4{ }^{\circ} \mathrm{C}$. The supernatant containing fragmented DNA was separated from the intact DNA in the pellet before DNA assay.

\subsection{Analysis of DNA fragmentation. Colorimetric method}

The DNA contents of both fractions obtained by ultracentrifugation were measured by a stoichiometric diphenylamine reaction [7]. The absolute amount of DNA was determined by comparison with a standard reference curve generated from calf-thymus (linear: $2-80 \mu \mathrm{g}$ ) and by reading the optical density at $595 \mathrm{~nm}$. The percentage (\%) DNA fragmentation was calculated by the ratio ( $\mu$ g supernatant DNA $) /(\mu \mathrm{g}$ supernatant DNA $+\mu \mathrm{g}$ pellet DNA $) \times 100$

\subsection{DNA electrophoresis}

DNA was separated by electrophoresis on $1.5 \%$ agarose gels in TBE buffer containing $89 \mathrm{mM}$ Tris, $89 \mathrm{mM}$ boric acid and $2 \mathrm{mM}$ EDTA, pH 8.4 at $10 \mathrm{~V}, 30 \mathrm{~mA}$ [19]. An aliquot of microsomal lysate $(20 \mu \mathrm{l})$ was mixed with $10-20 \mu \mathrm{l}$ solution containing $0.05 \%$ bromophenol blue, $40 \%$ sucrose, $100 \mathrm{mM}$ EDTA and $0.5 \%$ SDS. Standard DNA ( $\lambda$ EcoRI/Hind III digest 125-21226 bp) was used as control. Gels were stained with $0.5 \mu \mathrm{g} / \mathrm{ml}$ ethidium bromide, examined under UV light and photographed with a IBI quick shooter device.

\subsection{Measurement of \%S-phase and DNA ploidy}

Aliquots (80-100 mg) of frozen tumour powder was gently dispersed in $1.5 \mathrm{ml} 0.04 \mathrm{M}$ Tris, $0.5 \mathrm{M}$ sucrose, $1.5 \mathrm{mM} \mathrm{MgCl} 2 \mathrm{pH} 7.4$ using a loose-fitting teflon pestle. The resulting homogenate was filtered through several layers of nylon (mesh: 210 and $53 \mu \mathrm{m}$ ). The filtrate was layered onto a double layer of sucrose $(1.5$ and $1.75 \mathrm{M})$ according to Dressler et al. [12] and centrifuged at $1500 \times \mathrm{g}$ for $45 \mathrm{~min}$ at $4{ }^{\circ} \mathrm{C}$. The supernantant was removed and the nuclei (in the pellets) were washed with minimal essential medium (MEM) containing $10 \%$ fetal calf serum (FCS). There were $2 \times 10^{4}-2 \times 10^{6}$ nuclei per $100 \mathrm{mg}$ frozen pulverized tumour. The nuclear fraction was lysed and DNA stained by mixing the nuclei with $0.1 \%$ sodium citrate, $0.3 \%$ Nonidet $\mathrm{P}$ (NP-40), $0.05 \mathrm{mg} / \mathrm{ml}$ propidium iodide and $0.02 \mathrm{mg} / \mathrm{ml} \mathrm{RNase} \mathrm{A} \mathrm{(Sigma)} \mathrm{for} 10 \mathrm{~s}$, and incubated for $30 \mathrm{~min}$ at $40^{\circ} \mathrm{C}$. The fraction was centrifuged and nuclei resuspended in fresh staining solution, homogenized by passage through a 27-gauge needle and finally filtered through $37-\mu \mathrm{m}$ nylon mesh immediately before measuring in a Becton Dickinson (BD) FACscan flow cytometer. The \%S-phase and DNA index (DI) were estimated after collection of at least 10,000 events with a BD Cell-Fit program and the polynomial model for calculations. \%S-phase was measured in the first aneuploid (hypodiploid or hyperdiploid) populations. $\% \mathrm{~S}$-phase values of additional diploid subpopulations were excluded from the group of truly diploid tumours. DNA diploid tumours had a DI of 1; DNA aneuploid tumours had a hypodiploid DNA content when the DI was less than 0.96, and a hyperdiploid DNA content when the DI was 1.1-1.9. The mean coefficient of variation (CV) at the G0/G1 mean peak was always less than 5\% [41]. Isolated human peripheral blood lymphocytes fixed with ethanol were used as internal diploid DNA/G0-G1 control cells. 


\section{Results}

Table 1 summarizes the values obtained for the \%S-phase, \%DNA fragmentation, estrogen (ER) and progesterone (PR) receptors for the 110 samples of breast tissue with invasive carcinoma, and their division into three groups according to the DNA ploidy status. All the values varied greatly, indicating a non-Gaussian distribution in all tumour groups, as illustrated in the histogram plots (Figs 1 and 2). Hence, they can be adequately described by their median values (Table 2). The median value of $\% \mathrm{~S}$-phase fraction for the entire population was $8 \%$, quite close to the overall median value of 5.8\% reported for 1084 breast tumours [12]. The lowest median value of \%DNA fragmentation $(0.38 \%)$ was found for apoptosis in breast tumours with a DNA hypodiploid index, whilst the highest $(2.57 \%)$ was measured in tumours with a diploid DNA index, but with lymph node metastases. DNA hyperdiploid tumours had a median \%DNA fragmentation 4 times higher than that of the DNA hypodiploid group. They also had the highest median \%S-phase fraction (16\%) which was 1.5 -fold higher than the median reported by Dressler et al. [12]. The greatest value of \%DNA fragmentation (62\%) was measured only once, in a DNA hyperdiploid tumour. DNA diploid tumours had the lowest median proliferative capacity (6\%), regardless of the metastatic status, but lymph node involvement was associated with the highest median DNA fragmentation and the highest median ER concentration (Table 2). However, microsomal fractions prepared from these tumours and analyzed for DNA by agarose gel electrophoresis did not show evidence of ladder suggestive of internucleosomal fragmentation, nor of non-random DNA cleavage into large fragments ( $>22 \mathrm{kbp}$ ) (Fig. 3). Analysis of the relationship among parameters indicated an imbalance in favour of proliferation, especially for the DNA hypodiploid tumours, as indicated by the $\% \mathrm{~S}$-phase/\%DNA fragmentation ratio. Its value contrasted with the correspondent ER/PR ratio which was close to one, as the median values for both receptors were low in this group (Table 2). Hyperdiploid DNA tumours had the highest ER/PR ratio (4.1), but only a positive ER median value.

Table 1

Range values for \%S-phase, \%DNA fragmentation, ER/PR receptors measured in DNA hypodiploid, diploid and hyperdiploid breast cancer tumours

\begin{tabular}{lccc}
\hline & $\begin{array}{c}\text { Hypodiploid } \\
(n=10)\end{array}$ & $\begin{array}{c}\text { Diploid } \\
(n=71)\end{array}$ & $\begin{array}{c}\text { Hyperdiploid } \\
(n=29)\end{array}$ \\
\hline \%S-phase & $2.0-18.0$ & $0.4-38.0$ & $3.0-56.0$ \\
$\%$ DNA fragmentation & $0.0-29.9$ & $0.0-16.4$ & $0.0-62.0$ \\
ER (fmol/mg) & $0.1-149$ & $0.0-165$ & $0.1-304$ \\
PR (fmol/mg) & $0.0-39.1$ & $0.0-483$ & $0.0-93.6$ \\
\hline
\end{tabular}

$n=$ number of cases.

Table 2

Median values \pm 1 standard error of the median for $\%$ S-phase and \%DNA fragmentation

\begin{tabular}{lcccrrrr}
\hline DNA & $n$ & \%S-phase & $\begin{array}{c}\text { \%DNA } \\
\text { fragmentation }\end{array}$ & $\begin{array}{c}\text { \%S-phase/\%DNA } \\
\text { fragmentation }\end{array}$ & ER & PR & ER/PR \\
\hline Overall diploid & 71 & $6 \pm 0.7^{* *}$ & $1.68 \pm 0.1$ & 3.6 & 14.6 & 6.2 & 2.3 \\
Diploid met - & 55 & $6 \pm 0.8^{* *}$ & $1.38 \pm 0.2$ & 4.3 & 11.2 & 4.9 & 2.3 \\
Diploid met + & 16 & $6 \pm 2.0^{* *}$ & $2.57 \pm 0.4$ & 2.3 & 28.4 & 9.2 & 3.1 \\
Hypodiploid & 10 & $7.5 \pm 4.5^{*}$ & $0.38 \pm 0.2^{*}$ & 19.7 & 5.0 & 1.2 \\
Hyperdiploid & 29 & $16 \pm 2.7$ & $1.96 \pm 0.5$ & 8.2 & 10.6 & 2.6 \\
\hline
\end{tabular}

ER and PR, estrogen and progesterone receptors; met, metastases.

${ }^{*} 2 p<0.01,{ }^{* *} 2 p<0.001$ significantly different when compared to the hyperdiploid values by the Mann-Witney $U$-test. 

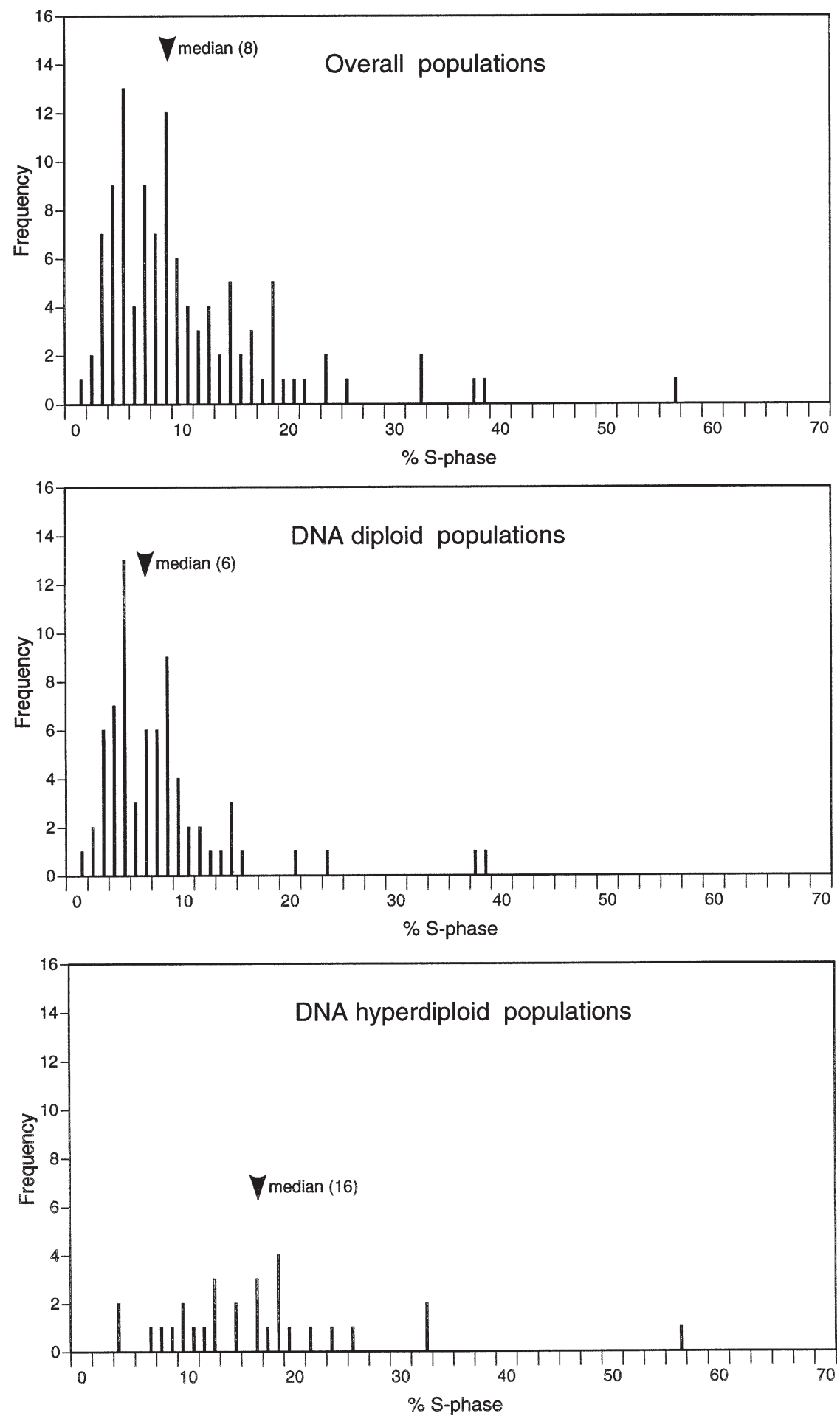

Fig. 1. Frequency distributions of $\%$ S-phase values for 110 samples of breast tumours and for the tumours divided according to the DNA ploidy. 

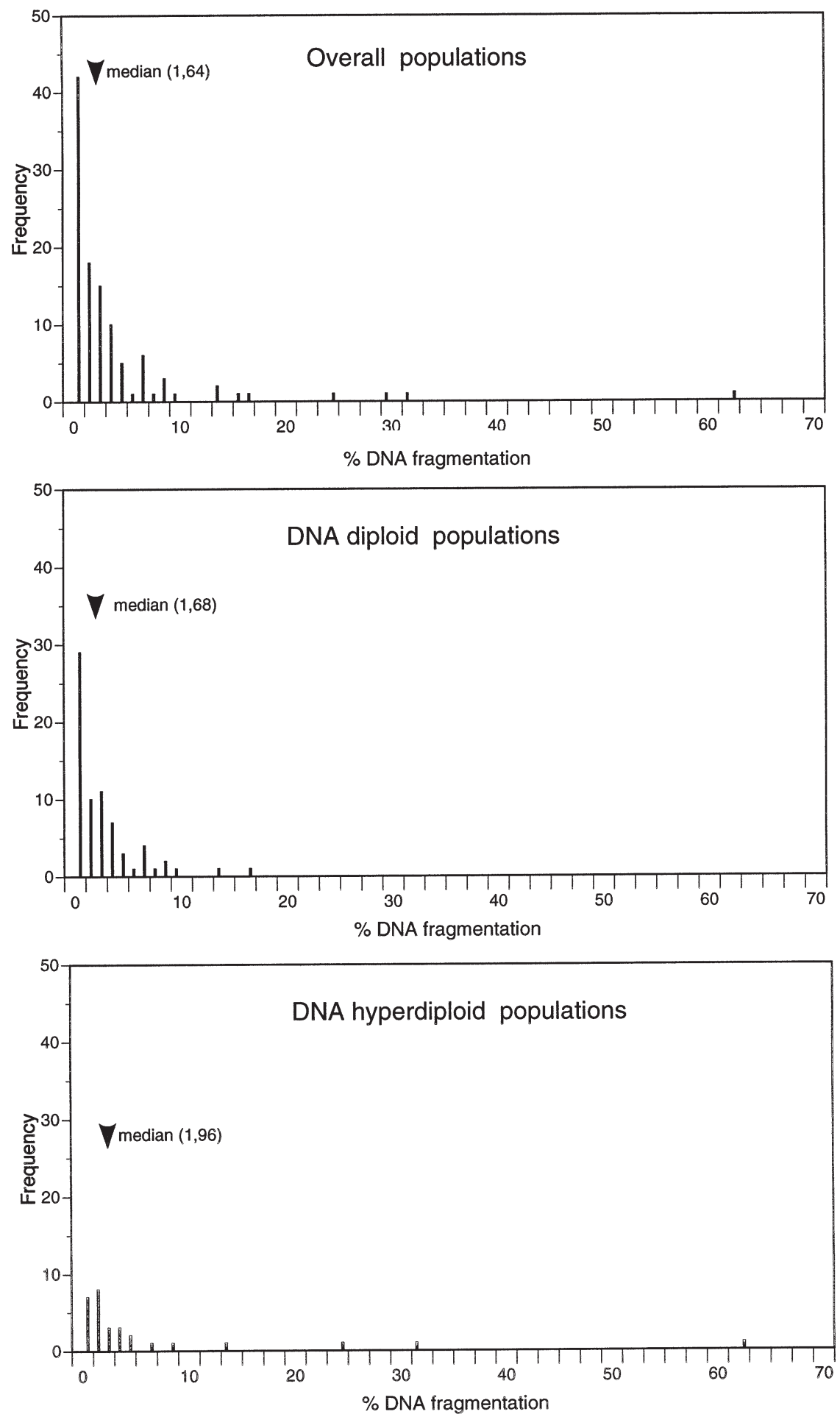

Fig. 2. Frequency distributions of \%DNA fragmentation values for 110 samples of breast tumours and for the tumours divided according to the DNA content. 


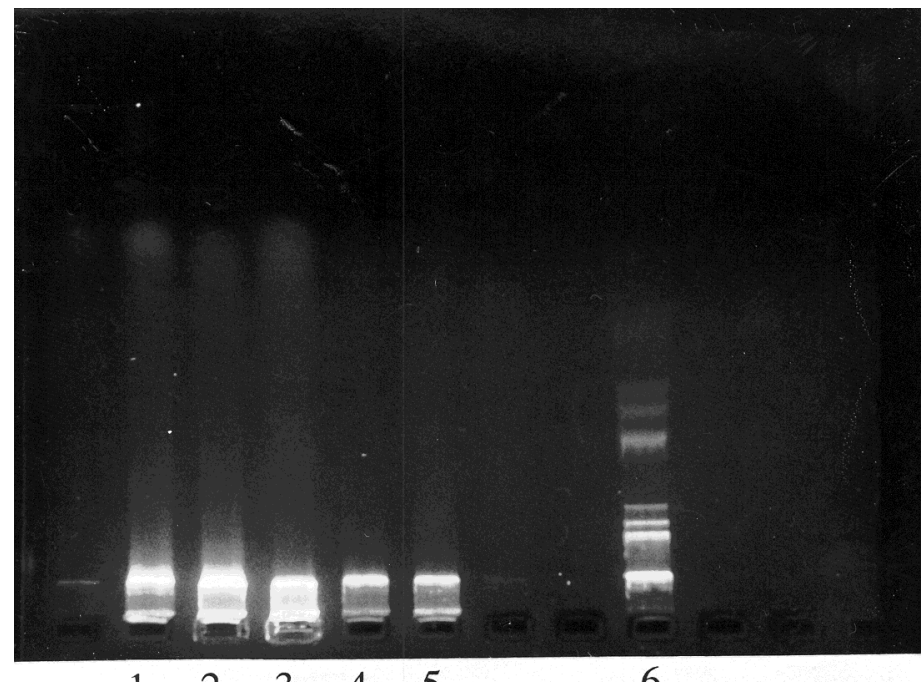

$\begin{array}{lllll}1 & 2 & 3 & 4 & 5\end{array}$

6

Fig. 3. Electrophoretic analysis of DNA fragments on a 1.5\% agarose gel. Lane 1, Ca with DI 0.85; lane 2, Ca with DI 1.25; lane 3, Ca with DI 1.72; lane 4, Ca with DI 2.51; lane 5, Ca with DI 2.69; lane 6, standard DNA ( $\lambda$ EcoRI/Hind III digest 125 bp-22 kbp). Ca, carcinoma; DI, DNA index.

\section{Discussion}

The results of the present study indicate that the frequency of measurable apoptosis is low in most human breast tissues with invasive carcinoma. Apoptosis was quantitatively assessed in microsomal membranes obtained by ultracentrifugation of homogenates from frozen breast tissue specimens by determining the fragmented DNA. Although percentage DNA fragmentation values varied greatly, the median frequency of apoptosis ranged from 0.38 to $2.57 \%$ for all tumours regardless of the DNA ploidy, but the lowest median frequency was in breast tumours with a hypodiploid DNA index. This residual apoptosis measured biochemically on 110 breast carcinoma specimens is consistent with recent data indicating an average apoptotic frequency of $1 \%$, determined by morphometry on histological sections from 15 cases of invasive breast cancer [43]. A previous study aimed to determine the proliferative activity within the epithelial cells of histologically "normal" human breast and of histologically diagnosed pathology (fibroadenoma, fibrocystic changes, carcinoma) in the same breasts has shown that the apoptotic index (AI) measured on histological sections was reduced in "normal" epithelium from breasts having fibrocystic changes $(0.17 \%)$ and carcinoma $(0.19 \%)$ compared to "normal" breasts with fibroadenoma alone $(0.27 \%)$ and to neoplastic tissues, namely, fibroadenoma $(0.27 \%)$ and carcinoma $(0.42 \%)$ [1]. Thus, apoptosis seems to be a relatively rare phenomenon in breast cancer and its frequency is significantly lower than in several cell culture systems. For example, most MCF-7 cells deprived of estrogen for 10 days became detached and showed non-random cleavage of nuclear DNA into the 50 and $300 \mathrm{kbp}$ fragments typical of apoptosis, but very few had the classical morphology of apoptotic cell death or internucleosomal DNA fragmentation [44]. The cells remaining attached were morphologically viable and had no apoptotic features [44]. Preliminary results obtained in our laboratory indicate that most MCF-7 and estrogen-independent SKBR-3 mammary cancer cells blocked in the G0 and/or G1 phase by treatment for 4 days with the $\mathrm{Ca}^{++}$ionophore A23187 (calcimycine) undergo apoptosis, with classical ultrastructural features, DNA fragmentation, altered permeability and a subdiploid region of cell cycle. The majority of thymocytes and human peripheral 
blood mononuclear cells (PBMNC) cultured for three days with the glucocorticoid dexamethasone contain apoptotic figures $[19,48]$. Physiologically active breast tissue contains apoptotic cells but has an apoptotic frequency consistently less than the mitotic frequency [3]. The mean number of apoptotic figures per lobule in the breasts of pregnant women, assessed by morphological inspection varied from 0.41 to 1.13 throughout pregnancy, whilst the breasts of lactating women had a mean frequency of only 0.04. There was a direct correlation with the mitotic frequency, which was $1.23-1.43$ in the breasts of pregnant women, and only 0.02 in the breasts of lactating women [3]. However, mammary gland involution, which follows weaning, occurs mostly by apoptosis [42]. The frequency of measurable apoptosis may be generally low in normal and neoplastic tissues because this is a natural process which is residual in living tissues. The real rate of cell death in tissues cannot be readily estimated probably because apoptosis is very rapid and most apoptotic cells are swiftly removed, thus escaping detection [6]. Other authors have previously reported that apoptosis is a rapid process in human as well as in animal tissues [16,36]. Second, the rate of removal of apoptotic elements by phagocytes may vary with the ploidy and proliferative status of the tissue. On the other hand, in vivo abrogation of apoptosis may concern cell elements that are committed to death, but are in the latent or initial stages of the process, and so undetectable by the methods presently available [28]. The extremely low residual apoptosis in hypodiploid DNA tumour tissues $(0.38 \%)$ is inversely related to their proliferative capacity, as indicated by the $\% \mathrm{~S}$-phase. In these tumours the median $\% \mathrm{~S}$-phase is slightly higher (7.5\%) than the median \%S-phase (6\%) of diploid DNA tumours, but is only half that of hyperdiploid DNA carcinomas (16\%), which also have the highest percent apoptotic cells (1.96\%). The optimal median cut-off point for S-phase fraction was set at $7 \%$ for DNA diploid cases and $12 \%$ for the DNA aneuploid cases, so that our results (6 and 16\%, respectively) are well in line with proliferative capacity found in previous reports [12,23]. Our findings suggest that there is an imbalance between residual apoptosis and cell growth in breast tumours when compared to physiologically active and resting human breast tissues $[3,16]$, as documented by the $\% \mathrm{~S}$-phase/\%DNA fragmentation ratio. This is particular high in hypodiploid DNA tumours. The hypodiploid and hyperdiploid DNA tumours also had low levels of ER and PR, indicating that apoptosis is no longer or poorly regulated by estrogens in these aneuploid carcinomas. It has been shown recently that the expression of the bcl-2 gene, which controls apoptosis, is mainly associated with the steroid receptor status and with low grade/estrogenreceptor positivity in slowly proliferating node-negative breast carcinomas [2] but inversely correlated with the Ki-67 growth fraction in breast carcinomas [11]. Clinical studies have shown that there is a correlation between the synthesis of anti-apoptotic bcl-2 protein and the estrogen receptor content of normal tissues [39] and invasive breast carcinomas [18,22]. When cells of the human breast cancer cell line MCF-7 are exposed to $\beta$-estradiol, their content of bcl-2 mRNA is increased, but not that of bax mRNA, indicating that steroid sex hormones can inhibit apoptosis by stimulating the production of the anti-apoptotic protein bcl-2 [44]. In conclusion, the routine determination of residual apoptosis in breast tissues with invasive carcinoma may not yet have any clinical relevance, because the morphologically apparent process is rare in these tumours, at least as measured by conventional procedures. However, if adequate methods become available that can identify and quantify the early or initial phases of apoptosis, similar to the exposure of phosphatidylserine on the outer leaflet of the plasma membrane in lymphocytes [15], or the activation of signal transduction and transport membrane enzymes [19], then assessment of the apoptotic potential could become relevant [26]. It could give a clearer indication of spontaneous cell loss, the proliferative capacity, the susceptibility to chemical treatment and, finally, the aggressiveness of a breast tumour, and thus provide a predictive information. 


\section{Acknowledgements}

This study was supported by grants from the Swiss National Science Foundation no. 31-39161. Mrs Antonella Camponovo and Morena Ghisletta are thanked for their skilful technical assistance. The English text was edited by Dr. Owen Parkes.

Part of this study was presented at the 8th International Symposium on Diagnostic Quantitative Pathology, Amsterdam, 1994.

\section{References}

[1] D.J. Allan et al., Reduction in apoptosis relative to mitosis in histologically normal epithelium accompanies fibrocystic change and carcinoma of the premenopausal human breast, J. Pathol. 167 (1992), 25-32.

[2] M. Barbareschi et al., bcl-2 and p-53 expression in node-negative breast carcinoma, Hum. Pathol. 27 (1996), 11491155.

[3] S. Battersby and T.J. Anderson, Proliferative and secretory activity in the pregnant and lactating human breast, Wirchows Arch. Pathol. Anat. 413 (1988), 189-196.

[4] M.A. Blankenstein, Comparison of ligand binding assay and enzyme immunoassay of estrogen receptor in human breast cancer cytosol, Breast Cancer Res. Treat. 17 (1990), 91-98.

[5] M.P. Bronner, C. Culin, J.C. Reed and E.E. Furth, The bcl-2 proto-oncogene and the gastrointestinal epithelial tumor progression model, Am. J. Pathol. 146 (1995), 20-26.

[6] W. Bursch, S. Paffe, B. Putz, G. Barthel and R. Schulte-Herman, Determination of the length of the histological stages of apoptosis in normal liver and in altered hepatic foci of rats, Carcinogenesis 11 (1990), 847-853.

[7] K.A. Burton, Study of the condition and mechanism of diphenylamine reaction for the colorimetric estimation of deoxyribonucleic acid, Biochem. J. 62 (1956), 315-323.

[8] D.A. Carson and J.M. Ribeiro, Apoptosis and disease, Lancet 341 (1993), 1251-1254.

[9] S.C. Chow, M. Weis, G. Kass, T.H. Holmström, J.E. Eriksson and S. Orrenius, Involvement of multiple proteases during Fas-mediated apoptosis in T-lymphocytes, FEBS Lett. 364 (1995), 134-138.

[10] L. Dini, M. Ruzittu and L. Falasca, Recognition and phagocytosis of apoptotic cells, Scan. Microscopy 10 (1996), 239-252.

[11] C. Doglioni, A.P. Dei Tos, L. Laurino, C. Chiarelli, M. Barbareschi and G. Viale, The prevalence of bcl-2 immunoreactivity in breast carcinomas and its clinicopathological correlates, with particular reference to estrogen receptor status, Wirchows Arch. 424 (1994), 47-51.

[12] G.L. Dressler, L.C. Seamer, M.A. Owens, M.C. Clark and W.L. McGuire, DNA flow cytometry and prognostic factors in 1331 frozen breast cancer specimens, Cancer 61 (1988), 420-427.

[13] M.J. Duffy, P. O’Grady, D. Devaney, L. O’Sioran, J.J. Fennelly and H.J. Lijnien, Urokinase-plasminogen activator, a marker for aggressive breast carcinomas, Cancer 62 (1988), 531-533.

[14] H.F. English, N. Kyprianou and J.T. Isaacs, Relationship between DNA fragmentation and apoptosis in the programmed cell death in the rat prostate following castration, Prostate 15 (1989), 233-251.

[15] V.A. Fadok, D.R. Voelker, P.A. Campbell, J.J. Cohen, D.L. Bratton and P.M. Henson, Exposure of phosphatidylserine on the surface of apoptotic lymphocytes triggers specific recognition and removal by macrophages, J. Immunol. 148 (1992), 2207-2211.

[16] D.J.P. Ferguson and T.J. Anderson, Ultrastructural observation on cell death by apoptosis in the resting human breast, Wirchows Arch. 393 (1981), 193-203.

[17] D.J.P. Ferguson and T.J. Anderson, A morphological study of the changes which occur during pregnancy in the human breast, Wirchows Arch. Pathol. Anat. 401 (1983), 163-175.

[18] J.M.W. Gee et al., Immunocytochemical localization of bcl-2 protein in human breast cancers and its relationship to a series of prognostic markers and response to endocrine therapy, Int. J. Cancer 59 (1994), 619-628.

[19] R. Graber and G.A. Losa, Changes in the activities of signal transduction and transport membrane enzymes in CEM lymphoblastoid cells by glucocorticoid-induced apoptosis, Anal. Cell. Pathol. 8 (1995), 159-176.

[20] Y.A. Hannun and C.M. Linardic, Sphingolipid breakdown products: anti-proliferative anf tumor-suppressor lipids, Biochim. Biophys. Acta 1154 (1993), 223-236.

[21] Y.A. Hannun, Functions of ceramide in coordinating cellular responses to stress, Science 274 (1996), 1855-1859.

[22] J. Hurlimann, B. Larrinaga and D.L.M. Vala, bcl-2 protein in invasive ductal breast carcinomas, Wirchows Arch. 426 (1995), 163-168.

[23] O.P. Kallionemi et al., Improving the prognostic value of DNA flow cytometry in breast cancer by combining DNA index and S-phase fraction, Cancer 62 (1988), 2183-2190. 
[24] M.K. Keane, S.A. Ettenberg, G.A. Lowrey, E.K. Russell and S. Lipkowitz, Fas expression and function in normal and malignant breast cell lines, Cancer Res. 56 (1996), 4791-4798.

[25] I.F. Kerr, A.H. Wyllie and A.R. Currie, Apoptosis: a basic biological phenomenon with wide ranging implications in tissue kinetics, Br. J. Cancer 26 (1972), 239-257.

[26] J.F.R. Kerr, C.M. Winterford and B.V. Harmon, Apoptosis. Its significance in cancer and cancer therapy, Cancer 73 (1994), 2013-2026.

[27] N. Kyprianou, H.F. English, N.E. Davidson and J.T. Isaacs, Programmed cell death during regression of MCF-7 human breast cancer following estrogen ablation, Cancer Res. 51 (1991), 162-166.

[28] Y.A. Lazebnik, S. Cole, C.A. Cooke, W.G. Nelson and W.C. Earnshaw, Nuclear events of apoptosis in vitro in cell-free mitotic extracts: a model system for analysis of the active phase of apoptosis, J. Cell Biol. 123 (1993), 7-22.

[29] M.E. Lippman et al., Growth regulation of human breast carcinoma occurs through regulated growth factor secretion, J. Cell Biochem. 35 (1987), 1-16.

[30] P. Lipponen, S. Aaltoma, V.M. Kosma and K. Syrianen, Apoptosis in breast cancer as related to histopathological characteristics and prognosis, Eur. J. Cancer 30A (1994), 2068-2073.

[31] G.A. Losa and M. Alini, Sulfated proteoglycans in the extracellular matrix of human breast tissues with infiltrating carcinoma, Int. J. Cancer 54 (1993), 552-557.

[32] G. Majno and I. Joris, Apoptosis, oncosis and necrosis, Am. J. Pathol. 146 (1995), 3-15.

[33] P. Martikainen, N. Kyprianou, R.W. Tucker and J.T. Isaacs, Programmed cell death of nonproliferating androgenindependent prostatic cancer cells, Cancer Res. 51 (1991), 4693-4700.

[34] M. Nakajima, T. Irimura and G.L. Nicolson, Heparanases and tumor metastasis, J. Cell Biochem. 36 (1988), 157-167.

[35] F. Oberhammer, W.J. Wilson, C. Dive, I.D. Morris, J.A. Hickman, A.E. Wakeling, P.R. Walker and M. Sikorka, Apoptotic death in epithelial cells; cleavage of DNA to 300 and/or $50 \mathrm{~kb}$ fragments prior to or in the absence of internucleosomal fragmentation, EMBO J. 12 (1993), 3679-3684.

[36] B.A. O'Brien, B.V. Harmon, D.P. Cameron and D.J. Allan, Beta-cell apoptosis is responsible for the development of IDDM in the multiple low-dose streptozotocin model, J. Pathol. 178 (1996), 176-181.

[37] P.X. Petit, H. LeCoeur, E. Zorn, C. Dauguet, B. Mignotte and M.L. Gougeon, Alterations of mitochondrial structure and function are early events of dexamethasone-induced thymocyte apoptosis, J. Cell Biol. 130 (1995), 157-166.

[38] J.C. Reed, bcl-2 and the regulation of programmed cell death, J. Cell Biol. 194 (1994), 1-6.

[39] J.C. Sabourin, A. Martin, J. Baruch, J.B. Truc, A. Gompel and P. Poitout, bcl-2 expression in normal breast tissue during the menstrual cycle, Int. J. Cancer 59 (1994), 1-6.

[40] R.A. Schwartzman and J.A. Cidlowski, Apoptosis: the biochemistry and molecular biology of programmed cell death, Endocrine Rev. 14 (1993), 133-151.

[41] T.V. Shankey, P.S. Rabinowitch, B. Bagwell, K.D. Bauer, R.E. Duque, D.W. Hedley, B.H. Mayall and L. Wheeless, Guidelines for implementation of clinical DNA cytometry, Cytometry 14 (1993), 472-477.

[42] R. Strange, F. Li, S. Saurer, A. Burkhardt and R.R. Friis, Apoptotic cell death and tissue remodelling during mouse mammary gland involution, Development 115 (1992), 49-58.

[43] H.A.M. van de Schepop, J.S. de Jong, P.J. van Diest and J.P.A. Baak, Counting of apoptotic cells: a methodological study in invasive breast cancer, J. Clin. Pathol. Mol. Pathol. 49 (1996), M214-M217.

[44] T.T.Y. Whang and J.M. Phang, Effects of estrogen on apoptotic pathways in human breast cancer cell line MCF-7, Cancer Res. 55 (1995), 2487-2489.

[45] J.W. Wilson, A.E. Wakeling, I.D. Morris, J.A. Hickman and C. Dive, MCF-7 human mammary adenocarcinoma cell death in vitro in response to hormon-withdrawal and DNA damage, Int. J. Cancer 61 (1995), 502-508.

[46] A.H. Wyllie, J.F.R. Kerr and A.R. Currie, Cell death: the significance of apoptosis, Int. Rev. Cytol. 68 (1980), 251-306.

[47] A.H. Wyllie, Apoptosis and regulation of cell numbers in normal and neoplastic tissues: an overview, Cancer Metastasis Rev. 11 (1992), 95-103.

[48] A.H. Wyllie, Glucocorticoid-induced thymocyte apoptosis is associated with endogenous endonuclease activation, Nature 284 (1980), 555-556. 


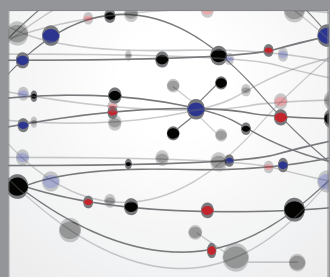

The Scientific World Journal
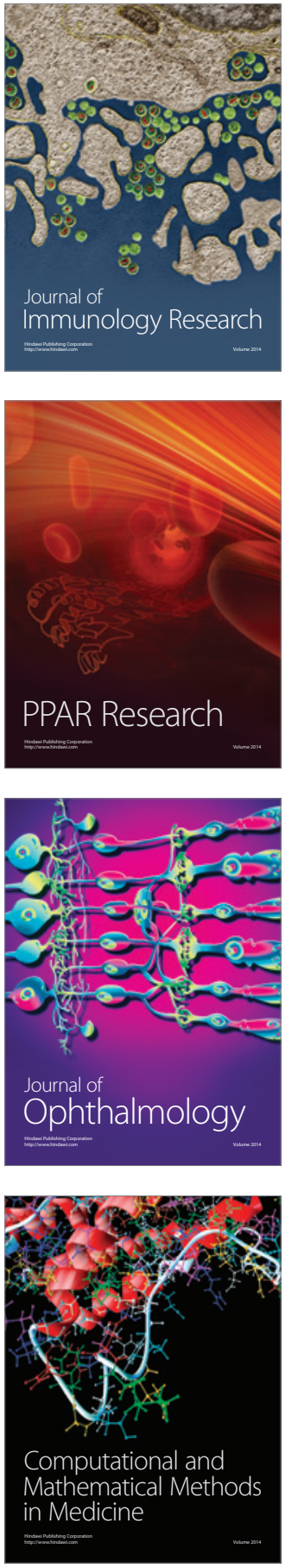

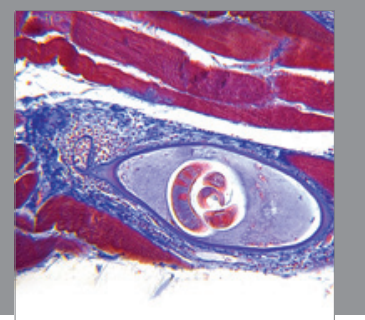

Gastroenterology

Research and Practice
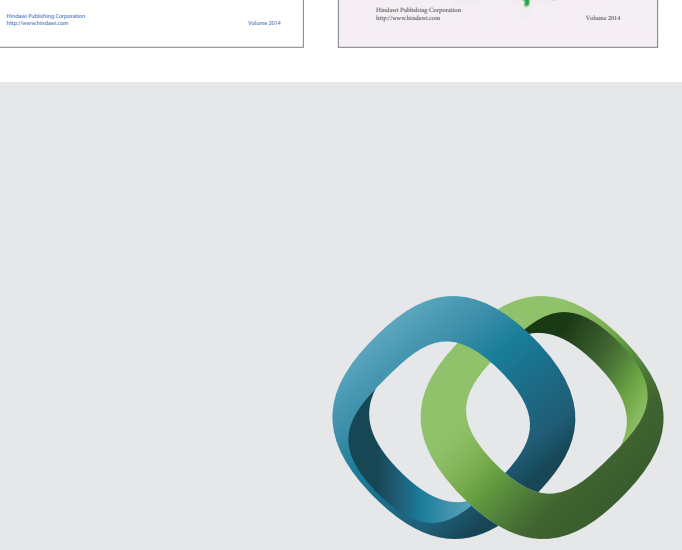

\section{Hindawi}

Submit your manuscripts at

http://www.hindawi.com
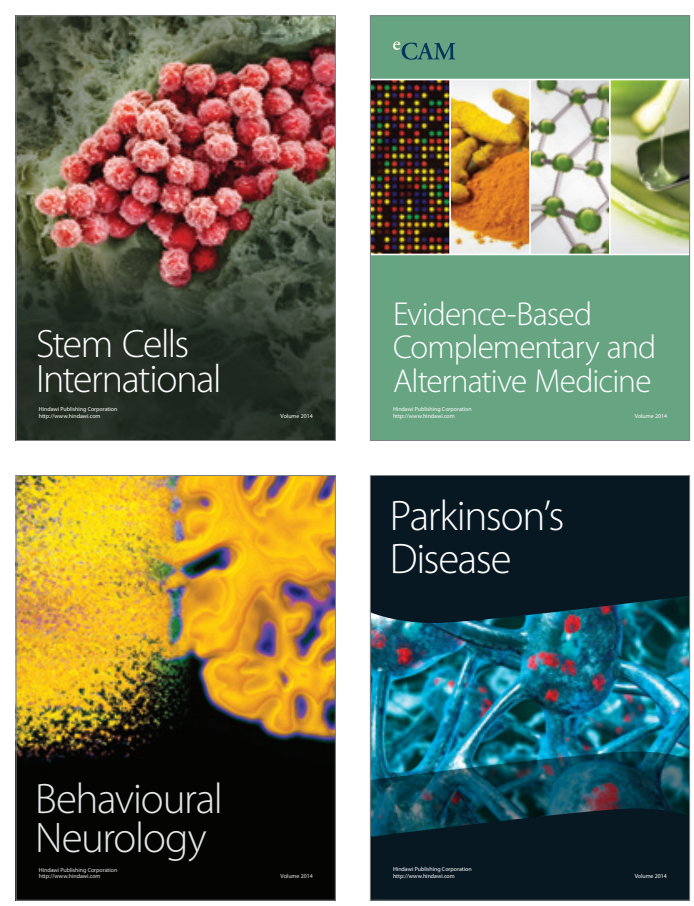

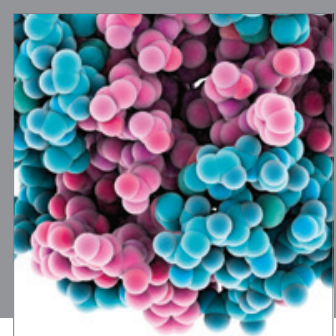

Journal of
Diabetes Research

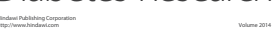

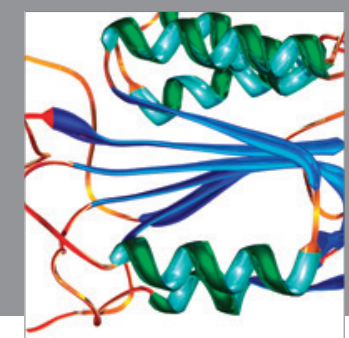

Disease Markers
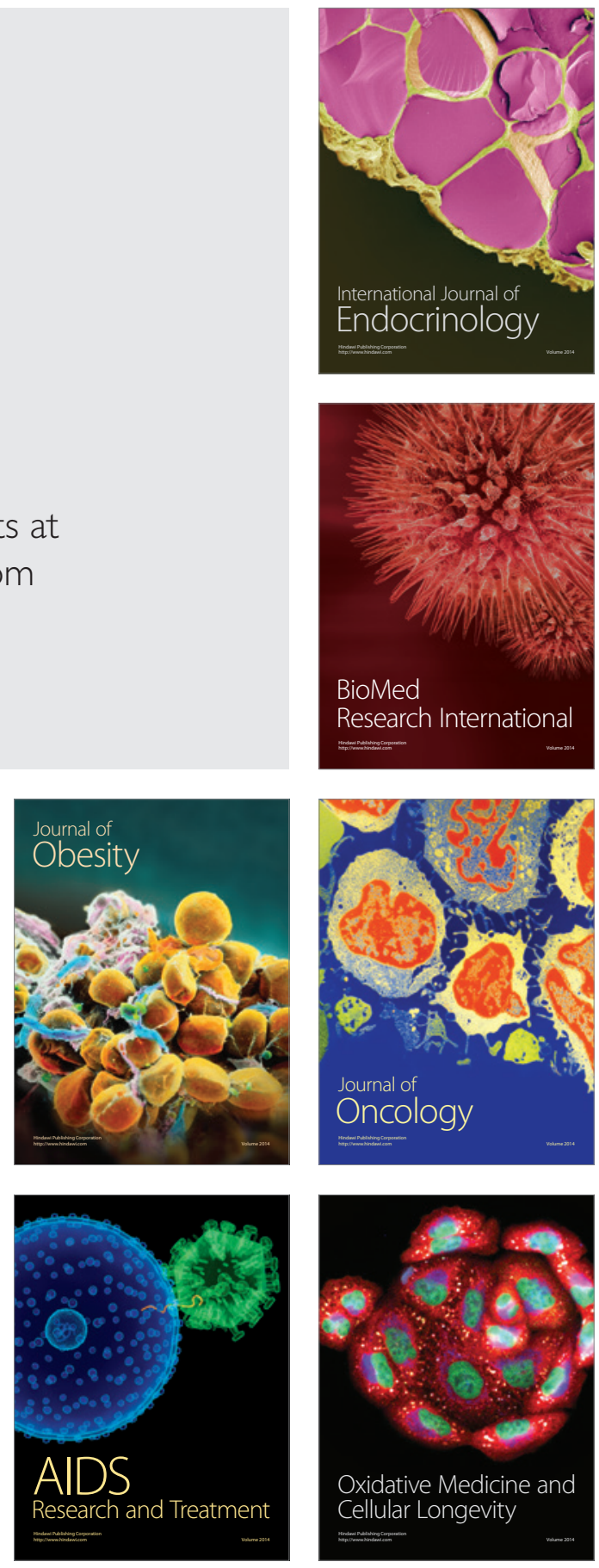